\title{
O TEATRO JUDAICO DE LÍNGUA ÍDICHE NA CRÍTICA TEATRAL DE L. S. VYGÓTSKI
}

\section{YIDDISH JEWISH THEATER IN L. S. VYGOTSKY'S THEATRICAL CRITIQUE}

\author{
Priscila Nascimento Marques*
}

\begin{abstract}
Resumo
$\mathrm{O}$ artigo tem por objetivo apresentar alguns aspectos da formação de um teatro judaico de língua ídiche na Rússia, seus desafios e principais características, para, em seguida, comentar uma série de resenhas escritas por L. S. Vygótski (1896-1934) acerca das apresentações da companhia de teatro dirigida por Menachem Rubin, as quais tiveram lugar na cidade de Gomel (atual Bielorrússia), no ano de 1923. As resenhas acompanham as inovações trazidas pelo teatro judaico no contexto das vanguardas russas, mas também seus paradoxos e inconsistências. O olhar sobre a produção da província revela, ainda, as diferenças em relação ao que se faz nas grandes capitais. Por fim, as resenhas trazem à tona a ligação de Vygótski com tradições e temas judaicos, aspecto frequentemente negligenciado de sua biografia e que só recentemente tem recebido maior atenção.
\end{abstract}

Palavras-chave: Teatro Ídiche, Crítica Teatral, Teatro Soviético.

\section{Abstract}

The essay has the objective of presenting some aspects of the formation a Jewish theater spoken in Yiddish in Russia, its challenges and main features. Later we intend to comment a series of reviews by L. S. Vygotsky (1896-1934) on the performances of a theatrical company directed by Menachem Rubin that took place in Gomel (now Belarus) in 1923. The reviews follow the innovations brought by the Jewish theater in the context of Russian avant-garde but also its paradoxes and inconsistencies. The look on provincial productions also reveals the differences in relation to what was made in big centers. At last, the reviews provide an

\footnotetext{
* Doutora em Literatura e Cultura Russa pela Faculdade de Filosofia, Letras e Ciências Humanas da Universidade de São Paulo.
} 
overlook on Vygotsky's relations to Jewish themes and traditions, an important aspect often neglected in its biography that just recently has received more attention.

Keywords: Yiddish Theater, Theatrical Critique, Soviet Theater. 
O teatro cotidiano deve morrer [...] este é um experimento, uma busca pela forma, um tatear, trata-se de material para trabalhos futuros, se me for possivel ainda trabalhar.

Evguêni Vakhtángov ${ }^{1}$

L. S. Vygótski (1896-1934), que, mais tarde, se tornaria um dos mais eminentes psicólogos russos de todos os tempos, é autor de uma série de textos publicísticos sobre teatro e literatura, produzidos no começo de sua carreira e divulgados em periódicos regionais de Gomel, os quais só recentemente têm sido descobertos por estudiosos de sua vida e obra ${ }^{2}$.

Assim, o presente artigo tem por objetivo apresentar alguns aspectos da formação de um teatro judaico de língua ídiche na Rússia, seus desafios e características principais, para, em seguida, comentar as resenhas de Vygótski, publicadas em 1923, no periódico Nach ponediélnik, sobre as apresentações da companhia teatral judaica dirigida por Menachem Rubin $^{3}$. As severas críticas feitas por Vygótski a essas montagens serão destrinchadas e revistas sob o pano de fundo da produção do teatro ídiche moscovita, o Goset (Gosudárstvenyi Evréiskii Teatr). Buscaremos compreender as apreciações de Vygótski sobre os erros e acertos dos espetáculos resenhados como contribuições para a construção, na província, de um teatro judaico mais afinado com os avanços da cena da capital.

No século XIX, havia, na Rússia, Ucrânia, Bielorrússia e Polônia, inúmeras companhias itinerantes judaicas, mais ou menos profissionais. Encenavam peças judaicas populares e operetas nacionais ou europeias. Tais grupos mantinham uma tradição antiga e restrita, repetiam procedimentos e formas estabelecidas e estavam distantes da produção contemporânea (TAMACHIN, 1966, p. 431). Abraham Goldfaden (1840-1908), considerado

\footnotetext{
${ }^{1}$ Vakhtángov sobre a montagem de $O$ dibuk do teatro Habima, citado por AZIZIAN, I. A. Aleksandr Bykhóvski. Moscou: Galart, 2007, p. 87.

2 Tal produção foi objeto de minha pesquisa de Doutorado, O Vygótski incógnito: escritos sobre arte (19151926) (MARQUES, 2015). A pesquisa foi financiada pela CAPES e o conteúdo deste artigo apresenta parte dos resultados obtidos.

${ }^{3}$ Menachem Rubin (1886-1962) foi um cantor, ator e diretor nascido em Adamów (Polônia). Trabalhou para diversas companhias itinerantes judaicas na Rússia. Dirigiu a companhia "Kunst Vinkl” de Kiev, apresentou-se por toda Rússia com Clara Young, atuou em 1927 com Julius Adler em Gomel. Em 1931, emigrou para os Estados Unidos, mas continuou excursionando pela Europa e Argentina (informações obtidas na tradução de Steven Lasky da biografia feita por Zalmen Zylbercweig - autor de Leksikon fun Yidishn Teater -, disponível em: $<$ http://www.museumoffamilyhistory.com/yt/lex/R/rubin-menachem.htm>).
} 
o pai do teatro ídiche moderno, foi uma figura fundamental para o estabelecimento de uma tradição teatral judaica. Inicialmente, escreveu comédias e farsas; mais tarde, dedicou-se a operetas históricas, obras que gozaram de grande popularidade. Tratava-se de peças musicais ecléticas, marcadas por sentimentalismo e comicidade. Peças históricas, como Bar Kokhba, traziam um viés nacionalista romântico que refletia os sentimentos protossionistas dos anos $1880^{4}$. Tais sentimentos nacionais, especialmente após os pogroms de 1881-12, foram importantes para o estabelecimento do ídiche como língua literária, além do intenso processo de modernização, industrialização e formação de um público leitor. Segundo Picon-Vallin, o teatro judaico que se popularizou na Rússia tsarista, na zona de residência (tchertá osiédlost), caracteriza-se por efeitos melodramáticos, gritos, lágrimas e operetas de gosto duvidoso. Funcionava como uma espécie de "sobrevivência básica, compromisso caótico entre um gosto profundo pela teatralidade, encarnada por Goldfaden, e as constantes imposições do governo" (PICON-VALLIN, 1973, p. 46).

O teatro ídiche foi, depois da imprensa, a segunda instituição responsável pela formação de uma cultura ídiche entre os judeus russos - particularmente, os adeptos do Haskalá ${ }^{5}$. A adoção do ídiche como língua literária e a formação de uma intelligentsia ídiche surgiu da necessidade de aproximação entre a elite intelectual e o povo "não educado". Assim, a cultura ídiche cumpriu as tarefas de unificar o povo judaico em torno de uma língua e, principalmente, de democratizar ideias e produtos culturais (FISHMAN, 2005). Nesse contexto, o teatro ídiche "está ligado ao povo por sua língua, ao trabalho educativo dos maskilim e também ao movimento socialista desenvolvido pelo Bund ${ }^{6}$ que se opõe ao

\footnotetext{
${ }^{4}$ Essa visão sobre a peça é contestada por Quint: “O jovem Bar Kokhba convoca uma arrasada comunidade judaica a lutar contra os conquistadores romanos até o último homem, opondo-se ao ancião Eliezer, que pregava a aceitação do domínio romano. Bar Kokhba ama a filha de Eliezer, Dina, e ela é capturada pelos romanos, que esperam usá-la como presa para capturar Bar Kokhba, mas ela estraga os planos deles com sua morte precoce. Histórias do teatro ídiche sustentam que a temática radical da peça (rebelião) incitou o governo tsarista a bani-lo, mas essa afirmação é patentemente falsa. Ao contrário, assim como muitos outros dramas históricos de Goldfaden [...] o tema da peça é conservador, exorta uma atitude conciliatória em relação ao domínio estrangeiro. A última cena, que representa o ataque romano a Betar, o último refúgio de Bar Kokhba, mostra a arrogância de Bar Kokhba como tão responsável pela carnificina como a crueldade romana.” (QUINT, 2007, p. 61).

${ }^{5}$ Iluminismo judaico. Os filósofos do Haskalá, conhecidos como maskilim, "incentivavam a educação secular e assimilação à cultura fora do gueto. Esses intelectuais e jovens judeus russos estavam ansiosos para compreender e entrar num mundo mais amplo e passaram a se reunir secretamente para estudar obras de filosofia, política e ciência, para absorver conceitos ocidentais considerados ameaçadores ou revolucionários para o establishment rabínico" (KAPLAN, 2007, pos. 179). Ao teatro coube a tarefa de propagar os ideais do movimento e disseminar a ilustração por entre o povo do gueto (PICON-VALLIN, 1973, p. 35).

${ }^{6}$ União Trabalhista Judaica (Algemeyner Yidisher Arbeter Bund), partido socialista secular judaico, que atuou na Lituânia, Polônia e Rússia entre 1897 e 1920.
} 
hebraico, língua dos rabinos conservadores e da elite letrada, e proclama o ídiche como língua materna" (PICON-VALLIN, 1973, p. 44-45).

Após a revolução, a figura central para a institucionalização de um teatro judaico de língua ídiche na Rússia foi Aleksei Mikháilovitch Granóvski (1890-1937). A ele foi confiada a tarefa de dirigir o Goset (Gosudárstvenyi Evréiskii Teatr). Granóvski, que havia trabalhado com Max Reinhardt na Alemanha, trouxe para o teatro judaico uma visão moderna e europeia que perpassava tanto seu sistema quanto o repertório escolhido (composto por obras judaicas e do simbolismo europeu). A companhia era composta por jovens atores não profissionais, que, segundo o diretor, tinham a capacidade de se entregar à alegria da criação. Seu objetivo era criar um teatro geral, "um templo de arte reluzente e criação alegre, um templo em que a prece é entoada na língua ídiche [...]. As tarefas do teatro mundial são as tarefas do nosso teatro, e somente a língua nos diferencia dos outros" (GRANÓVSKI, 1992, p. 145). Assim, temos que, desde seu nascimento como instituição, o teatro judaico foi fundado numa não contradição e não exclusivismo entre particular e geral.

Segundo Harshav, sua força estava na "combinação entre vanguarda, percepção multimídia da totalidade da experiência teatral e evocação de um mundo ficcional grotesco e emocional baseado no vibrante e exótico passado judaico" (1992, p. 16). A própria língua ídiche pode ser vista como símbolo desse movimento de particularização e complementaridade, uma vez que, ao mesmo tempo em que funcionava como identidade do povo judaico e o separava do mundo circundante, era uma ponte que o ligava a ele, visto que o folclore ídiche absorveu muitos elementos do folclore eslavo e europeu (HARSHAV, 1992, p. 56). Dessa forma, verifica-se que o novo teatro judaico é fundado sobre pilares dicotômicos do nacionalismo sionista e do internacionalismo comunista, misticismo messiânico e racionalismo revolucionário, drama poético e farsa crítica (GUINSBURG, 1994, p. 94).

A criação de Granóvski era atravessada pela noção wagneriana de Gesamtkunstwerk (obra de arte total), pois reunia música, literatura, folclore, dança e artes plásticas. Tal carnavalização de gêneros remontava ainda à tradição do Purim ${ }^{7}$. O novo teatro judaico da época da revolução buscou superar seus antecessores: de um lado, o teatro popular de

\footnotetext{
7 "O festival de Purim celebra a vitória dos judeus persas sobre Hamã, um inimigo repressor. Para os judeus russos, que haviam sido vítimas de proibição e perseguição por séculos, os tsares cristãos e seus governos eram como novos Hamãs. Ao celebrarem o novo teatro, Chagall pode ter usado esse carnaval Purim para celebrar a vitória da trupe sobre seu Hamã, ou seja, a queda do tsar que havia proibido o teatro judaico." (BLESSING, 1992, p. XII)
} 
entretenimento feito por Goldfaden entre 1876 e 1883; de outro, o individualismo e psicologismo de Peretz Hirshbein e Dovid Pinsky, entre 1905 e 1910.

O segundo protagonista desse processo foi Marc Chagall. Para Guinsburg, "a visão do pintor esteve presente em tudo, da cenografia aos figurinos e à maquilagem dos atores, e envolveu em sua carnavalizada dinâmica o próprio ritmo da interpretação e do espetáculo" (1994, p. 98). A arte de Chagall, Rabinovitch, Altman e Falk ajudou o teatro judaico a encontrar sua estética própria, uma vez que as artes plásticas eram a modalidade artística mais cultivada entre os judeus (PICON-VALLIN, 1973, p. 59). Como intérprete da mentalidade judaica e da vida na zona de residência, a contribuição chagalliana foi importante na busca do teatro de Granóvski por um colorido nacional.

Tanto Chagall quanto Granóvski incorporaram tendências contemporâneas e buscaram elementos da tradição judaica para produzirem obras profundamente conectadas com a atualidade e, ao mesmo tempo, portadoras de uma marca local e original. As montagens de Granóvski e as obras de Chagall são produtos de difícil classificação: negam o psicologismo, o realismo e o impressionismo que predominavam nos palcos russos no fim do século XIX e início do século XX. Suas produções se inserem, assim, no contexto da arte de vanguarda. É possível identificar, por exemplo, pontos de contato entre o sistema de Granóvski e a biomecânica de Meyerhold. Segundo Harshav, ele "preparava os atores para serem ágeis como acrobatas (o circo era uma inspiração para o teatro, como havia sido para Meyerhold e Eisenstein). A ênfase recaía sobre a linguagem, a música e o folclore” (HARSHAV, 1992, p. 43). A rejeição do naturalismo e a afirmação da teatralidade era um traço essencial dessa proposta estética, que, segundo Compton $(1999$, p. 3), se aproxima da noção de teatralidade de Evreinov:

O realismo puro e o simbolismo puro são ambos irreconciliáveis com a verdadeira natureza do teatro: o primeiro, pois produz um "duplo" inútil da vida (que não serve à arte, mas a extermina); o segundo, por ser essencialmente hostil ao prazer direto e franco da percepção visual. Ao professar, como eu faço, o princípio da teatralidade idealizada, defendo o realismo convencional ou realismo cênico, ou seja, a livre criação imaginativa de representação cênica que comanda a crença no espírito receptivo do espectador. (EVREÏNOFF, 1947, p. 377) 
Para Louis Adler, Granóvski fez com que as telas de Chagall se tornassem tridimensionais ${ }^{8}$. Ele desenvolveu uma biomecânica humanizada, que cria uma arte popular em que "a emoção estava sintetizada com a forma, em que os elementos da música, da fala, do movimento e do gesto eram todos parte de uma estrutura rítmica unificada" (ADLER, 1980, p. 42). Outro importante aspecto das montagens, observado por Litvakov, diz respeito à superação da emoção pura e à supremacia da racionalidade. O espetáculo é concebido como um todo arquitetônico, e o espectador é levado a revelações intuitivas ao entrar em contato com uma obra planejada racionalmente: "acima do 'reino da necessidade', acima da força espontânea de sentimentos não regulados - ele [o teatro judaico] coloca o 'reino da liberdade', a compreensão determinada e organizada" (LITVAKOV, 2008, p. 153).

A literatura ídiche foi relida por esse teatro; seus símbolos e motivos foram ressignificados, de forma a tornarem-se mais apropriados ao contexto revolucionário. A arte teatral era vista como meio para a libertação dos judeus do "escolasticismo rabínico insípido e ignorância burguesa" (VEIDLINGER, 1998, p. 395). Os textos clássicos eram retrabalhados; permanecia apenas o pano de fundo geral, os motivos folclóricos. O aspecto social era enfatizado, e conteúdos contemporâneos eram introduzidos (TAMACHIN, 1966, p. 439). A escolha por montar A feiticeira, de Goldfaden, em 1922, encontra-se alinhada com a difundida tendência no teatro de vanguarda de buscar fontes populares para renovação do teatro. Nesse caso, a fonte tem forte caráter nacional e remonta às farsas do purimspieler, ao folclore ídiche, à vida judaica na zona de residência (PICON-VALLIN, 1973, p. 71). Sobre a adaptação do texto original, Adler afirma:

Podemos nos perguntar por que Granóvski escolheu uma peça que era essencialmente um melodrama, a estória de uma pobre órfã vendida por sua madrasta a um harém turco. Granóvskaia diz que $A$ feiticeira era muito popular, e o tema atraía Granóvski - ele usou apenas o esqueleto. $\mathrm{O}$ sentimentalismo e a moralização foram substituídos por chistes atuais, canções e apartes para o público. Era composto por três cenários e oito cenas. Dois conhecidos escritores judeus, Litvakov e Dobrushin trabalharam o roteiro e também a sonoplastia (Granóvski queria representar o que Efros chamou de "uma sinfonia da teatralidade judaica") [...] Tematicamente $A$ feiticeira era uma celebração da morte dos "modos antigos", a morte das ideias religiosas e superstições desgastadas. Complementava a luta contra a estética antiga. Se Granóvski tinha uma mensagem, essa

\footnotetext{
${ }^{8}$ Esta afirmação não é suportada por Efros, cofundador do Goset, para quem Chagall "não tinha veia teatral. Ele não fazia cenários, mas painéis trabalhados em detalhes, com diferentes faturas, como se o espectador pudesse ficar diante deles, a curta distância, como numa exposição, e julgar a precisão e o charme deste campo de cor percebido por Chagall [...] Ele não queria conhecer a terceira dimensão, a profundidade do palco [...] Não adapta a perspectiva em que costuma desenhar os objetos de seu mundo à perspectiva cênica." (PICON-VALLIN, 1973, p. 66).
} 
era ela; e ela foi reiterada nos trabalhos que seguiram essa produção, embora a ênfase fosse diferente. (ADLER, 1980, p. 35-7)

Assim, em pleno florescimento da cena soviética durante os anos 1920, a contribuição do cosmopolita teatro judaico foi marcada pelos seguintes traços: um repertório misto; foco na formação de uma nova e polivalente geração de atores (encabeçada por Solomon Mikhoels); não realismo e não psicologismo; construtivismo cenográfico; incorporação de elementos da cultura popular judaica (revistos sob a ótica da sátira) e do modernismo russo. A interpretação era caracterizada por gestos exagerados, acrobacias, pesada maquiagem (que fazia lembrar máscaras e ocultava nuances emocionais) e representação de tipos sociais e do grotesco; os atores eram treinados para execução de uma verdadeira coreografia (VEIDLINGER, 1998, p. 385). Para Picon-Vallin, a leitura da tradição, aliada à ênfase no trabalho corporal, remete ainda ao Hassidismo, movimento que valoriza os aspectos emocionais do judaísmo e a comunhão com Deus no cotidiano (PICON-VALLIN, 1973, p. 74). Para Tomachin:

A arte dos atores do Gosekt ${ }^{9}$ era racional e convencional, desprovida do psicologismo sutil do MKhT [Teatro de Arte de Moscou]; a aparência externa do espetáculo estava sustentada pelo ritmo preciso, rigidamente trabalhado, pelo gesto acentuado, pelo agrupamento mímico e expressivo de personagens, pelo movimento contínuo, mas ajustado e cenicamente elaborado. Exatamente por isso a música tinha um papel tão importante no Gosekt, em geral, a música popular [...] A pantomima e a dança folclórica tinham lugar de destaque entre os procedimentos criativos do teatro. O Gosekt [...] buscava criar uma arte sintética, que combina organicamente palavra, canção e dança. (TOMACHIN, 1966, p. 440)

O fenômeno do Goset não se restringiu a Moscou, mas foi um grande sucesso nas cidades por onde excursionou (no verão de 1924, passou por Gomel, Odessa, Kharkov e Kiev), além de ter causado forte impressão em Berlim, na turnê europeia. Para Veidlinger, sua maior conquista, mais do que "converter os judeus do shtetl ao comunismo", consistiu na introdução de tendências modernistas nas isoladas vilas judaicas e na proporção de diversão e entretenimento para uma geração (VEIDLINGER, 1998, p. 397).

Passemos, agora, às resenhas de Vygótski. O primeiro texto trata das encenações de Silva e de A mensh zol men zein (Nach ponediélnik, $\mathrm{n}^{\mathrm{o}} 30$ ). Ao comentar a primeira, Vygótski ataca a futilidade da opereta em todos os seus elementos (dança, música, detalhes cômicos),

\footnotetext{
${ }^{9}$ Gosekt (Gosudarstvenyi Evreiskyi Kamernyi Teatr) foi o embrião que originou o Goset. Criado em Petrogrado por Granóvski em 1918, foi, por determinação de Lunatchárski, transferido para Moscou em 1920, quando retirou-se "kamernyi" (de câmara) de sua designação.
} 
que apareceram aqui desprovidos daquele "brilho do gracejo, do desembaraço, do divertimento, da elegância, que justificam a bobagem e a futilidade" (p. 241) ${ }^{10}$. Outro ponto criticado por Vygótski diz respeito à "judeificação" do tom. Ele sente falta de um estilo neutro de fala, que só poderia ser produzido por um teatro de repertório internacional e não cotidiano, algo que o crítico afirma não existir "entre nós" (isto é, na província). Quanto a esse ponto, Vygótski mostra-se de acordo com o projeto granovskiano de criar um teatro judaico que seja, ao mesmo tempo, universal.

A segunda peça é também uma opereta. Sobre ela, Vygótski afirma que a montagem se revelou incapaz de aproveitar plenamente o material lírico judaico, além de não ter encontrado o tom adequado para as cenas e motivos sérios no meio do "mar de disparates" (p. 242) da opereta. Tais elementos são apresentados, segundo Vygótski, de maneira superficial, como num drama qualquer, como num ensaio. A resenha é encerrada com breves comentários, majoritariamente positivos, sobre cada um dos atores (Lilina, Rosental, Merenzon e Klebanova). Essa estrutura é comum à maioria de suas resenhas: trata, inicialmente, da concepção geral da montagem, avalia seu (in)sucesso na tarefa de transpor o material dramático para o palco e finaliza tecendo comentários específicos sobre o desempenho dos atores. É também recorrente que as avaliações da montagem como um todo e do desempenho individual dos atores sejam discrepantes.

A resenha sobre o espetáculo $O$ dibuk (Nach ponediélnik, $\mathrm{n}^{\circ} 32$ ) ressalta a recepção positiva com que a crítica o acolhera. Vygótski fica particularmente entusiasmado com o fato de os debates terem concernido à "montagem como tal", isto é, como uma mise en scène é capaz de produzir novos efeitos no espectador. Sua resenha toma parte nesse debate. O texto, que havia sido consagrado pelo Habima de Moscou (teatro judaico de língua hebraica), cujas influências pendiam mais para o simbolismo e psicologismo do Teatro de Artes, era agora recontado por uma companhia ídiche, que tenta ser mais alinhada, esteticamente, com a proposta granovskiana. No entanto, as modestas proporções do teatro provinciano fazem com que ele se encontre no meio do caminho entre as inovações de Granóvski e um "camarismo judaico" (p. 243), isto é, um teatro menos elaborado e de amplitude e alcance significativamente menores. O que Rubin oferece é uma mistura não homogênea de

\footnotetext{
${ }^{10}$ Todas as resenhas citadas e comentadas no presente artigo foram traduzidas do russo por mim e estão inclusas na tese O Vygótski incógnito: escritos sobre arte (1915-1926) (MARQUES, 2015). A paginação junto às citações refere-se a esse trabalho.
} 
elementos incompatíveis. Além disso, aponta um grave problema em relação à técnica vocal dos atores.

A sequência de críticas negativas é interrompida: "Mas mesmo assim: bravo, Rubin!" (p. 244). Existe mérito na tentativa de se aproximar de uma nova linguagem teatral, das tendências contemporâneas que privilegiam o gesto convencional e estilizado, em detrimento do naturalista, isto é, "um gesto abertamente teatral, submetido ao estilo, não à verossimilhança psicológica ou cotidiana, pois o ator deste teatro interpreta não uma personalidade que o autor representou, não uma pessoa viva, mas uma imagem cênica" (p. 245). A imagem utilizada para sintetizar o significado d'O dibuk de Rubin é a de uma andorinha, a "primeira andorinha", que, segundo o provérbio russo, representa o primeiro passo de algo novo que está por vir. Essa é, contudo, aquela mesma andorinha que, sozinha, não faz verão (conforme um provérbio existente também em russo; cf. nota 5 da tradução). A imagem revela, assim, o caráter dual da montagem, que, efetivamente, apresenta inovações, mas elas não se encontram ainda completamente consolidadas e amadurecidas.

$\mathrm{Na}$ resenha seguinte (Nach ponediélnik, $\mathrm{n}^{\mathrm{o}} 33$ ), Vygótski comenta a presença de Goldfaden no teatro judaico contemporâneo. Segundo o crítico, estava na moda montar Goldfaden, pois se buscava um teatro teatralizado, limpo, não cotidiano ${ }^{11}$. A resposta do teatro judaico para a disputa entre a tendência naturalista e o teatro de convenção encontra-se na volta ao passado, na restauração do teatro de Goldfaden:

O princípio da arte teatral com valor em si mesmo e autônomo em relação à literatura, ao cotidiano, a todo tipo de representação da vida: essa é agora a posição mais avançada. É natural que muitos, com amor, se dirijam para trás, para o passado, pensando no futuro: lá, nas formas anteriores, primitivas, rudimentares dessa arte, eles encontram o teatro limpo, ainda não dominado por ninguém, o material nu do teatro como tal. Partindo de lá, eles esperam dar um salto mais fácil e direto para o teatro da atualidade e até para o do futuro. Assim é Goldfaden. (p. 246)

A iniciativa em si não lhe parece condenável. O teatro da vanguarda de Meyerhold, por exemplo, inspirou-se no teatro de feira (balagan). Trata-se da busca por um teatro embrionário, puro. É possível beber dessa fonte para fazer o novo, saltar para o futuro. Há, contudo, o risco de se produzir teatralismo, em vez de teatralidade. Na equação vygotskiana,

\footnotetext{
${ }^{11}$ Um fato muito significativo que marcou essa tendência foi a montagem de $A$ feiticeira, em 1922, pelo teatro de Granóvski. O texto foi adaptado, serviu de pretexto para a criação de um espetáculo popular alegre. Segundo Picon-Vallin, ao montar Goldfaden, "o Goset descobre o fato teatral em estado puro, a essência da teatralidade em uma explosão de alegria" (PICON-VALLIN, 1973, p. 69).
} 
teatralismo está para teatro, assim como vulgar está para popular. A montagem em questão revela-se contaminada por uma distorção, um "desvio mórbido" (p. 247) da fonte inspiradora, uma vez que apresenta Goldfaden numa chave naturalista, descaracterizando-o e retirando-lhe a originalidade e o interesse.

Vygótski observa aqui o choque entre duas tendências determinantes no teatro judaico. De um lado, sua origem popular, com os musicais e melodramas de Goldfaden; de outro, uma tentativa de refinamento, com escritores como Sholem Aleichen, Peretz e Asch, e dramaturgos como Gordin, que, inspirado por Ibsen, queria construir um teatro judeu realista, sério, sem dança ou música. Emigrado para os Estados Unidos em 1891, Gordin afrontou o desejo dos atores e do público de escapar da vida real e colocou-a no palco. Para ele, a tarefa do autor era lutar contra dogmas antigos e educar o público, não agradar ou entretê-lo (KAPLAN, 2007) $)^{12}$. Segundo Picon-Vallin, "a obra de Gordin participa do mesmo projeto renovador, mas em uma ótica mais naturalista, que introduz a verdade psicológica no teatro" (PICON-VALLIN, 1973, p. 42). Vygótski vê no teatro judaico provinciano uma mistura dessas tendências e tons, um ecletismo e hibridismo de resultados duvidosos: "o ator judeu provinciano contemporâneo, que passa por Gordin e Asch, que perde o brilhantismo e a variedade da teatralidade, que nada adquire em troca - o que ele pode dar a Goldfaden além de tédio, tédio e tédio?” (p. 247). Essa avaliação de Vygótski coincide com o que diz PiconVallin sobre as duas vertentes do teatro judaico: "O sucesso de Gordin é enorme, mas de um ponto de vista estritamente teatral, sua obra está muito atrás daquela de Goldfaden." (PICONVALLIN, 1973, p. 43).

A resenha seguinte é sobre a montagem de Bar Kokhba (Nach ponediélnik, $\left.\mathrm{n}^{0} 34\right)$. A opereta histórica de Goldfaden, que trata do espírito revolucionário, mesclando farsa e tragédia, tem, segundo Vygótski, lugar no repertório contemporâneo, desde que encenada de modo breve e como chiste. Faz-se necessário "entrelaçar os fios heroicos da alusão no tecido jocoso da bufonaria sincera e do pesquisador ingênuo da lenda fahistórica, interpretada precisamente como falseamento" (p. 250). Dessa forma, não se trata de transportar para o palco um episódio histórico, mas de tratá-lo como alegoria do espírito revolucionário.

\footnotetext{
${ }^{12}$ Apesar de ter construído sua carreira como dramaturgo nos Estados Unidos, a obra de Gordin ficou conhecida na Rússia com a turnê da companhia de Adler em 1907 e, principalmente, graças à Trupe Literária organizada em Varsóvia, em 1908, e dirigida por Rachel Kamínskaia, que "se dedica ao drama de costumes, apresentando o byt judaico tradicional de forma naturalista [...] Com Gordin, os atores judeus se viram forçados a compor personagens psicologicamente verossímeis que evoluem em situações realistas. É dessa forma que a influência de Stanislávski se faz sentir nas companhias judaicas, na medida em que existiam, nessa época, contatos específicos entre o teatro russo e o judaico." (PICON-VALLIN, 1973, p. 43).
} 
Vygótski sai em defesa da teatralidade, do caráter convencional da encenação: “como soam bem no palco as espadas de madeira quando elas são explicitamente de madeira e apenas interpretam o aço" (p. 250).

O segundo espetáculo resenhado nesse artigo é Der Yeshiva Bokher, adaptação de Hamlet feita por Tomachévski. Para Vygótski, diferentemente de Bar Kokhba, esse Hamlet judeu não possui nenhuma justificativa para o palco contemporâneo. O problema não reside na adaptação em si, que é um processo legítimo, mas, em particular, no resultado infeliz: “esse 'hamletzinho' é dos mais intoleráveis. [...] Ele nos faz retroceder cem anos, isso nem chega a ser ridículo, mas simplesmente sufocante, falta ar para respirar. E se até a prata antiga possui aspecto um tanto ridículo e antiquado aos nossos olhos, então como aceitar e receber esse guarda-roupa da bisavó totalmente empoeirado?” (p. 250).

Por fim, Vygótski ressalta que suas críticas à montagem (no primeiro caso) e à escolha do repertório (no segundo) não têm qualquer implicação em sua avaliação do trabalho dos atores. Atores e espectadores são vítimas desse teatro agonizante e decadente, que deve ser prontamente eliminado, para que um novo ocupe seu lugar. Vygótski enxerga um campo de luta, uma experiência dolorosa para o teatro judaico: "aquilo que agoniza tem de ser eliminado o quanto antes, já o que nasce tem de cortar o osso da gengiva. Tanto um quanto o outro surge da dor viva, mas ambos são necessários” (p. 251).

A seguir, Vygótski resenha os espetáculos realizados em homenagem à atriz Sofia Eidelman (Nach ponediélnik, $\mathrm{n}^{\mathrm{o}}$ 36). O primeiro deles, A pousada abandonada (Di Puste Kretshme), de Peretz Hirshbein, pertence à tradição teatral judaica de viés simbolista e impressionista, que, na opinião do crítico, soaria cômica se interpretada pelo teatro judaico cotidiano. A montagem é considerada bem-sucedida graças à interpretação de Eidelman. Seu trabalho apresenta uma saída para os desafios do teatro judaico, ao escapar do naturalismo puro - "os aspectos cotidianos se embaralham facilmente nela, são inexpressivos e pálidos" (p. 253) - e mostrar uma atuação desprovida de "cores cotidianas, pinturas típicas, etnográficas" (p. 253). Eidelman apresenta o desenho psicológico do personagem, o plano dos seus movimentos de alma. O tom da peça e o tom da interpretação estão em sintonia, o que, para Vygótski, constitui um grande mérito, haja vista que quase todas as suas críticas insistem nesse ponto.

A última resenha traz um comentário de cunho geral sobre a turnê (Nach ponediélnik, $\mathrm{n}^{\mathrm{o}}$ 37). Aqui, a crítica de Vygótski se dá em dois níveis: dirige-se tanto ao teatro judaico 
provinciano quanto à própria possibilidade de um teatro judaico. $\mathrm{O}$ teatro provinciano é visto como uma espécie de colcha de retalhos mal costurada. Apresenta um repertório com peças absoluta e qualitativamente diversas, heterogêneas. Há os experimentos com a teatralidade pura da tradição de Goldfaden (embora o resultado não passe de teatralismo) e com o teatro de câmara, naturalista - ambos sem sucesso. A encruzilhada em que se encontra o teatro judaico não é causal, tampouco decorre de uma geração de atores não talentosos. Ao contrário, em cada resenha, Vygótski destaca a qualidade do material humano, quando ele tem a chance de se manifestar e não é prejudicado pelos equívocos da montagem.

O problema do teatro judaico provinciano é o mesmo do teatro judaico em geral e, em última instância, reflete o paradoxo da própria existência judaica na Rússia pósrevolucionária: num contexto que tende ao internacionalismo e à ruptura com tradições arcaicas, a manifestação da particularidade nacional do judeu ocorreu pela chave da sátira e da negação de certos aspectos da cultura (especialmente da religião). O Goset especializou-se na satirização do misticismo e na atualização da questão judaica dentro da questão de classe. Ele aparece, assim, como um teatro "necessariamente antidogmático [...]. Por essa mesma razão, é também um teatro inapto à representação de heróis positivos, quaisquer que sejam, assim como à aplicação do dogma realista" (PICON-VALLIN, 1973, p. 172). Semelhante espírito encontra na língua ídiche seu veículo mais apropriado: “A língua ídiche [...] tem uma vocação crítica. Com sua estrutura linguística cotidiana, falada, familiar, o ídiche [...] se orienta para sua defesa e para a sátira social" (PICON-VALLIN, 1973, p. 78) ${ }^{13}$.

É assim que Vygótski antevê o paradoxo e explica a inviabilidade desse teatro: "Uma boa companhia judaica deste tipo não existe agora em parte alguma, nem poderia existir, e não adianta esperar por outros atores, pois eles não virão, nem nesta nem na próxima temporada, ou mesmo daqui a dois anos" (p. 256, grifos do autor). Não há saída. No campo de batalha entre diferentes tendências, o teatro judaico sai, inevitavelmente, derrotado, faz sofrer espectadores e atores em igual medida. A história do teatro judaico soviético, iniciada com Granóvski, evidencia sua criação em bases contraditórias, como um teatro universal e, ao mesmo tempo, particular, que incorpora diferentes tendências, mas que tem identidade e

\footnotetext{
${ }^{13}$ Em Semiótica da comunicação em ídiche, Harshav afirma que esta não é uma língua linear ou lógica. Sua estrutura deriva de uma "linguagem translógica", expressa quando se responde a uma pergunta com outra pergunta ou com um exemplo, quando se ilustra um ponto por meio de uma história, parábola, enigma, chiste, ou ainda com trocadilhos (HARSHAV, 1994, p.152).
} 
qualidades próprias. As inovações propostas pelo Goset repercutem de forma relativamente distorcida na província.

Assim, as resenhas de Vygótski são uma espécie de radiografia de como essa tendência agregadora gerou um teatro com problemas particulares. A mistura feita no teatro provinciano é ineficaz, desprovida de refinamento e de elaboração técnica, está geográfica e simbolicamente distante do que faziam Granóvski e Chagall com o Goset. Mas mesmo os resultados do teatro oficial da capital são colocados em xeque por Vygótski, no que se refere à sua capacidade de produzir novas formas, incorporando as tradições judaicas. O próprio Mikhoels (principal ator e, após a saída de Granóvski da URSS, diretor do Goset) reconheceu esse fato posteriormente: "Ao mostrar por meio do grotesco sua relação com esse obscuro período da história do povo judaico, o teatro passou ao largo do principal, isto é, do próprio povo" (apud TAMACHIN, 1966, p. 442). Restará sempre a questão: como permanecer judeu e se tornar soviético?

É a revolução que dá ao teatro judaico o direito à existência, mas podemos nos perguntar se ela oferece ao mesmo tempo as condições para que ele exista num plano que não seja o onírico. Pois, ainda que se tirem as mordaças dos judeus, ainda restam as correntes. Por isso, a revolução para o Goset é uma revolução na expressão, e não uma liberação autêntica. [...] A breve passagem de Granóvski pelo Goset é a história de uma ilusão, a abertura de um parêntese que logo será fechado, já que a realidade desmentiu as esperanças e aspirações dos judeus. (PICON-VALLIN, 1973, p. 172)

Os comentários finais do artigo fazem alusão a essas questões e soam melancólicos diante do prenúncio de algo que a história confirmará (os anos dourados do teatro judaico terminarão antes do final da década de 1920). Apesar disso, as últimas palavras são de exaltação desse teatro: um teatro coxo, mas com a "nossa coxeadura". Ressoa nesse "nossa" a voz do Vygótski-judeu, um homem preocupado e atento às questões nacionais. 


\section{Bibliografia}

ADLER, L. Alexis Granovski and the Jewish State Theater of Moscow. The drama review: TDR, vol. 24, $\mathrm{n}^{\mathrm{o}} 3,1980$.

AZIZIÁN, I. A. Aleksandr Bykhóvski: stupeni tvortchestvo-bytiia. Moscou: Galart. Dom Evréiiskoi Knígui, 2007.

BLESSING, J. Introduction. In: Marc Chagall and the Jewish theater. Nova Iorque: The Solomon R. Guggenheim Foundation, 1992.

EVREÏNOFF, N. Histoire du théatre russe. Paris: Éditions du Chêne, 1947.

FISHMAN, D. E. The rise of modern Yiddish Culture. Pittsburgh: University of Pittsburgh Press, 2005.

GRANOVSKI, A. Our goals and objectives. In: Marc Chagall and the Jewish theater. Nova Iorque: The Solomon R. Guggenheim Foundation, 1992.

GUINSBURG, J. Uma cena soviética: O teatro ídiche de estado. Revista USP, $\mathrm{n}^{0}$ 24, dezembro/fevereiro, 1994/1995.

HARSHAV, B. Chagall: Postmodern and fictional worlds in painting. In: Marc Chagall and the Jewish theater. Nova Iorque: The Solomon R. Guggenheim Foundation, 1992.

HARSHAV, B. The Moscow Yiddish Theater: Art on stage in the time of revolution. Nova Iorque e Londres: Yale University Press, 1992.

. The Semiotics of Yiddish Communication. In: What is Jewish Literature? Philadelphia: The Jewish Publication, 1994.

KAPLAN, B. Finding the Jewish Shakespeare: The life and legacy of Jacob Gordin. Nova Iorque: Syracuse University Press, 2007.

LITVAKOV, M. Five years of the State Yiddish Theater (Excerpts; 1924). In: HARSHAV, Benjamin. The Moscow Yiddish Theater: Art on stage in the time of revolution. Nova Iorque e Londres: Yale University Press.

MARQUES, P. N. O Vygótski incógnito: escritos sobre arte (1915-1926). Tese de Doutorado - Faculdade de Filosofia, Letras e Ciências Humanas da Universidade de São Paulo, 2015.

PICON-VALLIN, B. Le theater juif soviétique pendant les années vingt. Lausanne: La Cité, 1973. 
SHERMAN, J. (Ed). Dictionary of literary biography: Writers in Yiddish (vol. 333). Nova Iorque: Thomson Gale, 2007.

TAMACHIN, L. G. Evreiskii teatr. In: Istoriia Soviétskogo Dramatitcheskogo Teatra v chesti tomakh. Tom 2 (1921-1925). Moscou: Nauka, 1966.z

VEIDLINGER, J. Let's perform a miracle: the Soviet Yiddish State Theater in the 1920s. Slavic Review, vol. 57, $\mathrm{n}^{\mathrm{o}}$ 2, 1998. 